\title{
Atividade antibacteriana do óleo essencial da Lavandula Híbrida Grosso associada à gentamicina contra cepas de Staphylococcuus aureus
}

Antibacterial activity of the essential oil of the Lavandula Hibrida Grosso associated with gentamycin against Staphylococcus aureus strains

Actividad antibacteriana del aceite esencial de la Lavandula Híbrida Grosso asociada a la gentamicina contra las cepas de Estafilococo aureus

Maria Tays Pereira SANTANA ${ }^{1}$

Lucas Linhares GOMES ${ }^{1}$

Thallita Alves dos SANTOS

Filipe de Oliveira LIMA ${ }^{1}$

Sheyliane Rego MORAIS ${ }^{1}$

Aleson Pereira de SOUSA ${ }^{2}$

Maria Angélica Sátyro Gomes ALVES ${ }^{1}$

Gymenna Maria Tenório GUÊNES ${ }^{1}$

Heloisa Mara Batista Fernandes de OLIVEIRA ${ }^{3}$

Abrahão Alves de OLIVEIRA FILHO ${ }^{1}$

${ }^{1}$ Universidade Federal de Campina Grande (UFCG), Brasil

${ }^{2}$ Universidade Federal da Paraíba (UFPB), Brasil

${ }^{3}$ Hospital Universitário Ana Bezerra (UFRN), Brasil

\section{Resumo}

Staphylococcus aureus é uma bactéria que faz parte da microbiota natural do ser humano, podendo ser encontrada em inúmeras partes do corpo, como pele, narinas, cavidade oral e intestino. Esta bactéria é capaz de causar inúmeras doenças, exigindo assim um tratamento complexo por meio de antimicrobianos, que podem ser de origem sintética ou natural. O propósito desse trabalho foi avaliar a atividade antibacteriana do ósseo essencial da Lavandula Híbrida Grosso associado com o antimicrobiano gentamicina contra cepas de $S$. aureus. O caráter antibacteriano do óleo essencial da Lavandula Híbrida Grosso foi quantificado e qualificado pela técnica de microdiluição em caldo para a obtenção da CIM (Concentração Inibitória Mínima). Em seguida, realizou-se a associação do óleo essencial com o antimicrobiano gentamicina $(10 \mu \mathrm{g} / \mathrm{mL})$. A CIM (Concentração Inibitória Minima) foi de $128 \mu \mathrm{g} / \mathrm{mL}$ para a cepa em análise. Quanto a associação, foi observado um efeito sinérgico ao se associar a gentamicina com o óleo essencial da Lavandula Híbrida Grosso. Portanto, observou-se um efeito sinérgico ao se associar o óleo essencial em estudo com o antimicrobiano gentamicina.

Descritores: Anti-infecciosos; Fitoterapia; Microbiologia.

\section{Abstract}

Staphylococcus aureus is a bacterium that is part of the natural microbiota of humans, and can be found in numerous parts of the body, such as skin, nostrils, oral cavity and intestine. This bacterium is capable of causing numerous diseases, thus requiring a complex treatment by means of antimicrobials, which can be of synthetic or natural origin. The purpose of this work was to evaluate the antibacterial activity of the essential bone of the Lavandula Hibrida Grosso associated with the antimicrobial gentamicin against strains of S. aureus. The antibacterial character of the essential oil of Lavandula Hibrida Grosso was quantified and qualified by the broth microdilution technique to obtain MIC (Minimum Inhibitory Concentration). Then, the essential oil was combined with the antimicrobial gentamicin $(10 \mu \mathrm{g} / \mathrm{mL})$. The MIC (Minimum Inhibitory Concentration) was $128 \mu \mathrm{g} / \mathrm{mL}$ for the strain under analysis. As for the association, a synergistic effect was observed when combining gentamicin with the essential oil of Lavandula Hybrid Thick. Therefore, a synergistic effect was observed when associating the essential oil under study with the antimicrobial gentamicin.

Descriptors: Anti-Infective Agents; Phytotherapy; Microbiology.

\section{Resumen}

Staphylococcus aureus es una bacteria que forma parte de la microbiota natural de los humanos y se puede encontrar en numerosas partes del cuerpo, como la piel, las fosas nasales, la cavidad oral y el intestino. Esta bacteria es capaz de causar numerosas enfermedades, por lo que requiere un tratamiento complejo por medio de antimicrobianos, que pueden ser de origen sintético o natural. El propósito de este trabajo fue evaluar la actividad antibacteriana del hueso esencial de la Lavandula Hibrida Grosso asociada con la gentamicina antimicrobiana contra las cepas de S. aureus. El carácter antibacteriano del aceite esencial de Lavandula Hibrida Grosso se cuantificó y calificó mediante la técnica de microdilución en caldo para obtener MIC (concentración inhibitoria mínima). Luego, el aceite esencial se combinó con la gentamicina antimicrobiana $(10 \mu \mathrm{g} / \mathrm{ml})$. La MIC (concentración inhibitoria mínima) fue de $128 \mu \mathrm{g} / \mathrm{ml}$ para la cepa bajo análisis. En cuanto a la asociación, se observó un efecto sinérgico al combinar gentamicina con el aceite esencial de Lavandula Hybrid Thick. Por lo tanto, se observó un efecto sinérgico al asociar el aceite esencial en estudio con la gentamicina antimicrobiana.

Descriptores: Antiinfecciosos; Fitoterapia; Microbiología.

\section{INTRODUÇÃO}

Os Staphylococcus aureus (S. aureus), são cocos Gram e catalase - positivos, com aproximadamente 0,5 a 1,5 micrometro de diâmetro, imóveis, não esporuladas e em sua maioria não encapsuladas, esses microorganismos podem se apresentar de diversas formas que vão desde isolados, aos pares, em cadeias curtas, ou agrupados irregularmente, sendo esse último semelhante ao um cacho de uva ${ }^{1-3}$.

O gênero Staphylococcus pertence à família Micrococcae, junto como os gêneros Planococcus, Micrococcus e Stomatococcus, atualmente o gênero Staphylococcus possui 33 espécies, sendo 17 delas capazes de serem encontradas em amostras biológicas humanas, sendo esse gênero pertencente a microbiota da pele humana normal, além de outros sítios anatômico, dentre as espécies a de maior interesse médico é o $S$. aureus, por está diretamente relacionada com inúmeras infecções nos seres humanos ${ }^{1,2}$.

Essas infecções podem se localizadas ou está presente em múltiplos sítios, e, dependendo de sua localização e de outras características, recebem nomes distintos, como foliculite (infecção do folículo piloso); sico (bicho-do-pé); carbúnculo; antraz; furúnculos localizados na região cervical posterior; hordéolo (terçol); hidradenite (inflamação das glândulas sudoríparas); e impetigo ${ }^{4-6}$. Quando essas bactérias alcançam a corrente sanguínea elas podem ficar presas e se manterem nas válvulas e nos tecidos 
cardíacos, induzindo assim a endocardite bacteriana ${ }^{7}$.

Dessa maneira, existe uma preocupação diante de procedimentos odontológicos que sejam capazes de causar bacteremia transitória em pacientes que apresentam riscos para a endocardite, dentre as especialidades da odontologia a periodontia é que exige maior cuidado, já que lida com processos infecciosos onde há uma grande quantidade de patógenos somada ao tratamento que causa sangramento e assim permiti maior propagação de agentes microbianos para a circulação ${ }^{8}$.

Os tratamentos desses processos infecciosos são realizados mediante ao uso de antimicrobianos, classe de fármacos utilizados para o tratamento de doenças bacterianas, os quais se diferem uns dos outros de acordo com suas propriedades físicas, químicas, farmacológicas, dentro do espectro e mecanismo de ação ${ }^{9}$.

Assim, para que o tratamento de infecções bacterianas com o uso de antimicrobianos seja eficaz é necessário que alguns critérios sejam considerados como, a necessidade de que um alvo (ligante) exista dentro da célula bacteriana, a concentração do antibiótico alcance o alvo em quantidade suficiente, não podendo ocorrer inativação ou modificação estrutural do fármaco ${ }^{10}$.

Entretanto, quando essa finalidade terapêutica não é bem direcionada, no que se refere ao tempo de uso e dose, surge a seleção de patógenos resistentes no meio ambiente, que podem causar doenças de difíceis tratamento dentro da população. ${ }^{11}$ Surgindo dessa forma a necessidade de outras alternativas terapêuticas, como por exemplo, o uso de produtos naturais vegetais isolados ou associados aos antimicrobianos já existentes na clínica médica.

As plantas tem a capacidade de sintetizar cerca de 200.000 metabólitos secundários sendo também conhecido como fitoquímicos, dentre esses metabólitos, tem os compostos aromáticos que forma um importante grupo como os óleos essenciais. ${ }^{12}$ Os óleos essenciais, conhecidos também como óleos voláteis, óleos etéreos ou essência estão presentes nas plantas como produto natural e por ser um derivado do metabolismo secundário, desempenha um importante papel no mecanismos de defesa das plantas, contra outras plantas e predadores de maneira geral ${ }^{13-15}$.

O potencial farmacológico e as propriedades organolépticas dos óleos essenciais, se devem, geralmente à presença de terpenos, destacando os mono e os sesquiterpenos e de fenilpropanoides ${ }^{16}$.

Os óleos essenciais são largamente empregados na indústria farmacêutica, cosmética, alimentícia e agronômica por suas propriedades observadas na natureza, dentre as quais pode-se citar sua ação antibacteriana, atividades antifúngica e inseticida ${ }^{17}$.

Nesse contexto, o presente estudo tem como objetivo avaliar a atividade antibacteriana do óleo essencial da Lavandula Hibrida Grosso quando associado ao antimicrobiano gentamicina contra cepas de S. aureus.

\section{MATERIAL E MÉTODO}

- Substâncias-teste

O óleo essencial de Lavandula Híbrido Grosso foi adquirido da Indústria Via Aroma ${ }^{\circledR}$ (Porto Alegre - RS). Para a realização dos ensaios farmacológicos, a substância foi solubilizada em DMSO e diluída em água destilada. A concentração de DMSO (dimetilsulfóxido) utilizada foi inferior a $0,1 \% \mathrm{v} / \mathrm{v}$.

\section{- Antimicrobiano sintético}

Foi selecionado no presente estudo o antibiótico gentamicina $(10 \mu \mathrm{g} / \mathrm{mL})$. A concentração contida no disco de antibiótico é uma concentração padrão determinada pelo $\mathrm{CLSI}^{18}$. O estudo de observação de sensibilidade da cepa bacteriana frente ao antibiótico foi realizado através da técnica de difusão em meio sólido utilizando-se discos de papel de filtro (Newprov $\left.{ }^{1}\right)^{19}$.

\section{- Espécie Bacteriana e Meio de cultura}

O microorganismo utilizado foi a cepa clínica de Staphylococcus aureus (SA 101), proveniente do Laboratório de Microbiologia da Unidade Acadêmica de Ciências Biológicas do Centro de Saúde e Tecnologia Rural da Universidade Federal de Campina Grande.

A cepa foi mantida em meio Ágar Muller Hinton (AMH) a uma temperatura de $4{ }^{\circ} \mathrm{C}$, sendo utilizado para os ensaios repiques de 24 horas em $\mathrm{AMH}$ incubados a $35{ }^{\circ} \mathrm{C}$. No estudo da atividade antimicrobiana foi utilizado um inóculo bacteriano de aproximadamente $1,5 \times 10^{8} \mathrm{UFC} / \mathrm{mL}$ padronizado de acordo com a turbidez do tubo 0,5 da escala de McFarland ${ }^{20,21}$.

\section{- Determinação da Concentração Inibitória Mínima (CIM)}

A concentração inibitória mínima do óleo foi determinada pela técnica de microdiluição em caldo $^{20,21}$. Foi utilizada uma placa de 96 orifícios estéreis e com tampa. Em cada orifício da placa, foi adicionado $100 \mu \mathrm{L}$ do meio líquido Muller Hinton $(\mathrm{MH})$ duplamente concentrado. Em seguida, $100 \mu \mathrm{L}$ da emulsão do óleo na concentração inicial de 2048 $\mu \mathrm{g} / \mathrm{mL}$ (também duplamente concentrado), foram dispensados nas cavidades da primeira linha da placa. E por meio de uma diluição seriada em razão de dois, foram obtidas as concentrações de 1024, 512, 256, $128,64,32,16,8$ e $4 \mu \mathrm{g} / \mathrm{mL}$, de modo que na primeira linha da placa encontra-se a maior concentração e na última, a menor concentração. Por fim, foram adicionados $10 \mu \mathrm{L}$ do inóculo de aproximadamente $1-5 \times 10^{8} \mathrm{UFC} / \mathrm{mL}$ da espécie bacteriana nas cavidades.

Paralelamente, foi realizado o mesmo ensaio 
com o antibacteriano cloranfenicol, o controle positivo. Um controle de microorganismo foi realizado colocando-se nas cavidades $100 \mu \mathrm{L}$ do mesmo $\mathrm{MH}$ duplamente concentrado, $100 \mu \mathrm{L}$ de água destilada estéril e $10 \mu \mathrm{L}$ do inóculo de cada espécie. Para verificar a ausência de interferência no resultado pelos solventes utilizados na preparação da emulsão, no caso o DMSO, foi feito um controle no qual foi colocado nas cavidades $100 \mu \mathrm{L}$ do caldo duplamente concentrado, $100 \mu \mathrm{L}$ de DMSO e $10 \mu \mathrm{L}$ da suspensão bacteriana. Um controle de esterilidade do meio também foi realizado, onde foi colocado $200 \mu \mathrm{L}$ do MH em um orifício sem a suspensão das bactérias.

A placa foi assepticamente fechada e incubada a $35^{\circ} \mathrm{C}$ por $24 \mathrm{hs}$ em seguida foi realizada a leitura da CIM para o monoterpeno e o antibacteriano a qual foi definida como a menor concentração capaz de inibir visualmente o crescimento bacteriano verificado nos orifícios quando comparado com o crescimento controle.

\section{- Estudo da interferência do óleo essencial sobre o} efeito de antimicrobianos sintético

$\mathrm{O}$ estudo da interferência do óleo essencial sobre a efetividade dos antimicrobianos foi realizado através da técnica de difusão em meio sólido utilizando disco de gentamicina. O disco contendo o antimicrobiano na sua respectiva concentração foi embebido com $20 \mu \mathrm{L}$ da CIM do óleo essencial, e em seguida colocado em placa de Petri estéril contendo ágar Muller-Hinton inoculado com $1 \mathrm{~mL}$ da suspensão bacteriana. Após incubação das placas a $37^{\circ} \mathrm{C}$ por 48 horas, foi observada a interferência da CIM óleo essencial sobre o efeito do antimicrobiano sobre a cepa bacteriana ensaiada. Foi considerado como efeito sinérgico, quando o halo de inibição do crescimento microbiano formado pela associação teve um diâmetro $\geq$ que $2 \mathrm{~mm}$, quando comparado com o halo de inibição formado pela ação do antimicrobiano isoladamente. Quando a formação de halo de inibição decorrente da associação fosse de um diâmetro menor daquele desenvolvido pela ação isolada do antimicrobiano, era considerado efeito antagônico. Foi considerado como efeito indiferente, quando o de halo de inibição consequente à associação tivesse um diâmetro igual àquele consequente da aplicação isolada do antimicrobiano $^{16,20}$. Todos os ensaios foram realizados em duplicata.

\section{RESULTADOS E DISCUSSÃO}

O S. aureus apresenta uma distribuição ampla, visto que esse patógeno apresenta capacidade de dissecação assim como a temperaturas baixas, podendo se manter viável em partículas de poeira, esse agente microbiano pode ser encontrado na circulação do ser humano, sendo o seu principal reservatório, além de estar presente em diversas partes do corpo, como pele, fossas nasais, intestino e garganta $^{22-24}$.
Por ser um dos componentes da microbiota natural da pele, os pacientes que fazem uso de cateteres podem ser acometidos pelo $S$. aureus, através do local de inserção do cateter, esse agente microbiano alcançando assim a corrente sanguínea, podendo causar quadros de bacteremia, principalmente quando a microbiota abriga cepas de S.aureus à meticilina, sendo denominada como MRSA (S. aureus resistente a meticilina) ${ }^{25}$.

A resistência do $S$. aureus aos antimicrobianos tem sido desenvolvida por mutações em seus genes ou pela aquisição de genes resistente de outras bactérias de mesma espécie, essa resistência ocasiona alteração no sítio de ação do antibiótico, enquanto que a resistência por aquisição provoca a inativação ou destruição da droga ${ }^{26-28}$.

Dessa forma, o mau uso desses fármacos leva o aparecimento de microorganismos resistentes com capacidade de acumular e se disseminar, o que representa um sério para a população, devido a redução de fármacos efetivos, aumentando as complicações de pacientes hospitalizados e prologando sua estadia hospitalar, o que provoca um elevado gasto na saúde pública ${ }^{29}$. O estudo de Carvalho et al. ${ }^{30}$ afirma que aproximadamente $48 \%$ dos medicamentos atualmente usados no tratamento de inúmeras patologias derivam-se direta ou indiretamente de produtos de origem vegetal a partir de plantas medicinais, como por exemplo os óleos essenciais.

Alguns pesquisadores têm extraído óleos essenciais de várias plantas tais como: Origanum vulgare (orégano), Thymus vulgaris (Tomilho), Cinnamomum zeylanicum (Caneleira), Lippia alba, Lippia alba $f$. intermédia (Erva-cidreira), Ocimum basilicum (manjericão)e Salvia officinalis (Sálvia), os quais têm demonstrado atividade antimicrobiana frente a varios microrganismos, por exemplo: Salmonella sp., Bacillus cereus, Clostridium perfringens, Yersinia enterocolitica, Listeria monocytogenes, Staphylococcus aureus, Escherichia coli, Fusarium verticillioides, Salmonella Typhimurium e Salmonella Enteritidis ${ }^{31-34}$.

Como resultados nesta pesquisa observou-se que a CIM (Concentração Inibitória Minima) foi de $128 \mu \mathrm{g} / \mathrm{mL}$ para a cepa em análise. Em relação a associação do óleo essencial de Lavandula Híbrida Grosso com o antibiótico gentamicina, mostrou um aumento do tamanho do halo de inibição do antimicrobiano, sendo esse resultado obtido a partir da análise comparativa entre o halo de inibição na presença do antibiótico com halo de inibição na presença do antibiótico associado com o óleo essencial.

Nesse contexto, observou-se que o óleo essencial de Lavandula Híbrida Grosso quando associado ao antimicrobiano gentamicina apresentou uma excelente ação antibacteriana, efeito sinérgico, 
ao observar um aumento de $2 \mathrm{~mm}$ do halo de inibição, de acordo com os critérios estabelecidos por Lorian ${ }^{20}$. Portanto, na literatura existem estudos voltados à análise de associações de substâncias naturais com medicamentos sintéticos, como por exemplo, o estudo de Oliveira et al.(2006) o qual analisou quatro óleos essenciais de diferentes espécies vegetais associado com gentamicina contra $S$. aureus, nessa análise observou-se que os óleos Lippia sidoides, Plectranthus amboinicus, Conyza bonariensis e Eucalyptus citriodora apresentaram efeito antagônico, diferente do presente trabalho o qual demonstrou um efeito sinérgico revelando assim uma importância terapêutica do óleo essencial da Lavandula Hiíbrida Grosso ${ }^{35}$.

Tabela 1. Interferência do óleo essencial de Lanvandula Híbrido Grosso com o antibiótico sintético.

\begin{tabular}{c|c}
\hline Antibiótico & Microorganismo \\
\hline Gentamicina & $\begin{array}{c}\text { S. aureus } \\
\text { SA } 101\end{array}$ \\
\hline HIATB & $3,0 \mathrm{~mm}$ \\
\hline HIATB + OE & $3,2 \mathrm{~mm} \square$ \\
\hline
\end{tabular}

HIATB: halo de inibição na presença do antibiótico. OE: óleo essencial. Efeito sinérgico ( $\square$ ). Efeito antagônico $(\downarrow)$ Efeito indiferente $(*)$.

\section{CONCLUSÃO}

A partir dos resultados obtidos no presente trabalho, pode-se concluir que a associação do óleo essencial de Lavandula Híbrida Grosso com o medicamento convencional gentamicina se mostrou como uma terapia promissora no que se refere aos tratamentos de infecções bacterianas. No entanto, é importante que estudos mais detalhados sejam realizados, para que assim as aplicações de terapias baseadas em associações de produtos convencionais com produtos naturais sejam feitas com uma margem de segurança cada vez mais ampla.

\section{REFERÊNCIAS}

1. Cassetari VC, Strabelli T, Medeiros EAS. Staphylococcus aureus bacteremia : whats is the impacto f oxicillin resistance on mortality. Braz $\mathbf{J}$ Infect Dis. 2005;9(1):70-6.

2. Koneman EW, Allen SD, Janda WM, Schreckenberger PC, Winn WC. Diagnóstico Microbiológico: texto e atlas colorido. Medsi: Rio de Janeiro; 2001.

3. Trabulsi LR, Teixeira LM, Bueris V. Stahphylococcus aureus. In: Trabulsi LR, Alterthum F. Microbiologia. $4^{a}$ ed. São Paulo: Atheneu; 2004. p.175-82.

4. Andriolo A. Guias de medicina ambulatorial e hospitalar. São Paulo: Manole; 2005.

5. Braunwald E. Harrison Medicina Interna. 15. ed. Rio de Janeiro: Mcgraw-Hill Interamericana do Brasil; 2002.

6. Schechter M, Marangoni DV. Doenças infecciosas: conduta, diagnóstico e terapêutica. 2. ed. Rio de Janeiro: Guanabara Koogan; 1998.

7. Santos CAL, Silva AMR, Thomson Z, Matsuo T, Fernandes KBP, Deszan CC. Prevalência e fatores associados a doença periodontal em puérperas atendidas em maternidade pública de Londrina, Paraná. Espaço para Saúde. 2014; 15(1):37-46,

8. Lima HG, Lara VS. Aspectos imunológicos da doença periodontal inflamatória: participação dos mastócitos. Cient Ciênc Biol Saúde. 2013; 15(3):225-29.

9. Baptista, MGFM. Mecanismos de resistência aos antibióticos [dissertação]. Lisboa, Portugal: Universidade Lusófona de Humanidades e Tecnologia; 2013.

10. Costa ALP. Resistência bacteriana aos antibióticos: uma perspectiva do fenômeno biológico, suas consequências e estratégias de contenção [monografia]. Macapá: Curso de Ciências Biológicas, Departamento de Ciências Biológicas e da Saúde, UNIFAP;2016.

11. Orús P, Gomez-Perez L, Leranoz S, Berlanga M. Increasing antibiotic resistance in preservativetolerant bacterial strains isolated from cosmetic products. Int Microbiol. 2015;18(1):51-9.

12. Sharma PK, Sangwan NS, Bose SK, Sangwan RS. Biochemical characteristics of a novel vegetative tissue geraniol acetyltransferase from a monoterpene oil grass (Palmarosa, Cymbopogon martinii var. Motia) leaf. Plant Sci. 2013;203204:63-73.

13. Simões CMO, Schenkel EP. A pesquisa e a produção brasileira de medicamentos a partir de plantas medicinais: a necessária interação da indústria com a academia. Rev bras farmacogn. 2002;12(1):35-40.

14. Croteus R, Kutchan TM, Lewis NG. Natural products (secondary metabolites). Biochemistry and molecular biology of plants. 2000; 24:12501319.

15. Pinto AC, Silva DHS, Bolzani VDAS, Lopes NP, Epifanio RDEA. Produtos naturais: atualidades, desafios e perspectivas. Quím Nova. 2002;25(Supl 1):45-61.

16. Oliveira MB. Extração, Caracterização e avaliação da atividade larvacida do óleo essencial do Citrus Limon Linneo (limão) frente ao mosquito Aedes aegypti [dissertação]. São Luís: Universidade Federal do Maranhão; 2012.

17. Bakkali F, Averbeck S, Averbeck D, Idaomar M. Biological effects of essential oils - a review. Food Chem Toxicol. 2008;46(2):446-75.

18. Clinical and Laboratory Standard Institute (CLSI) - Approved standard M2-A7: performance standards for antimicrobial disk susceptibility tests. Seventh edition. Wayne-PA, 2003.

19. Vandepitte, J, Engbaek, K, Piot, P, Heuck, CC, Levanon, Y. Procedimentos laboratoriais em bacteriologia clínica. 2.ed. São Paulo: Santos; 1994.

20. Lorian VMD. Antibiotics in Laboratory Medicine. Willians \& Wilkins; 1991:739-788. 
21. Hadacek F, Greger H. Testing of antifungal natural products: methodologies, comparatibility of results and assay choice. Phytochem Anal. 2000;11:137-47.

22. Bannerman, T.L. (2003) Staphylococcus, Micrococcus, and Other Catalase-Positive Cocci That Grow Aerobically. In: Murray PR, Baron EJ, Jorgensen JH, Pfaller MA, Yolken RH (eds). Manual of Clinical Microbiology, 8th ed. American Society for Microbiology, Washington DC, 384-404.

23. Carvalho TL, Bezerin EN, Pestelli IP, Mímica L, Cardoso MRA. Monitoramento microbiológico sequencial da secreção traqueal em pacientes intubados internado na unidade de terapia intensiva pediátrica. J Pediatr. 2005;81(1):384-404.

24. Cavalcanti SM, França ERD, Cabral C, Vilela MA, Montenegro F, Menezes D, Medeiros AC. Prevalence of staphylococcus aureus introduced into intensive care units of a university hospital. Braz J Infect Dis.2005;9(1):56-63.

25. Gosbell IB. Diagnosis and management of cateterrelated bloodstream infections due to staphylococcus aureus . Intern Med J. 2005; 35(Suppl 2):455-625.

26. Bernard L, Vaudaux P, Rohner P, Huggler E, Armanet M, Pittet D et al. Comparative analysis and validation of differeent assays for glycopeptide susceptibility among methicilinresistant S.aureus strains. J Microbiol Methods. 2004;57(2):231-39.

27. Lima DC, Alvarez Abreu P, Freitas CC, Santos DO, Borges RO, Santos TC, et al. Snake venom: any clue for antibiootics and cam. Evid Based Complement Alternat Med. 2005;2(1):39-47.

28. Tavares W. Manual de antibióticos e quimioterápicos antiinfecciosos. 3.ed. São Paulo: Atheneu; 1996.

29. Siqueira CMM. Resistência aos antibióticos: o uso inadequado dos antibióticos na prática clínica. Rev Ofil. 2004;14(1):45-68.

30. Carvalho ACB, Nunes DSG, Baratelli TG, Shuqair NE. Aspectos da legislação no controle dos medicamentos fitoterápicos. T\&C Amazônia. 2007;5(11):26-32.

31. Busatta C, Mossi AJ, Rodrigues MRA, Cansian RL, Oliveira JVD. Evaluation of Origanum vulgare essential oil as antimicrobial agent in Sausage. Braz J Microbiol. 2007;38(4):610-16.

32. Dambolena JS, Zunino MP, López AG, Rubinstein HR, Zygadlo JA, Mwangi JW et al. Essential oils composition of Ocimum basilicum L. and Ocimum gratissimum L. from Kenya and their inhibitory effects on growth and fumonisin production by Fusarium verticillioides. Innovative Food Sci Emerg Technol. 2010;11(2):410-14.

33. Hussain AI, Anwar F, Sherazi STH, Przybylski R. Chemical composition, antioxidante and antimicrobial activities of basil (Ocimum basilicum) essential oils depends on seasonal variations. Food Chem. 2008;108(3):986-95.

34. Muñoz M, Guevara L, Palop A, Tabera J, Fernandez OS. Determination of the effect of plant essential oils obtained by supercritical fl uid extraction on the growth and viability of Listeria monocytogenes in broth and food systems using $\mathrm{fl}$ ow cytometry. LWT. 2008;42(1):220-27.

35. Oliveira RA, Lima EO, Vieir WL, Freire KRL, Trajano VN, Lima IO. Estudo da interferência de óleos essenciais sobre a atividade de alguns antibióticos usados na clínica, Rev bras farmacogn. 2006;16(1):77-82.

\section{CONFLITO DE INTERESSES}

Os autores declaram não haver conflitos de interesse.

\section{AUTOR PARA CORRESPONDÊNCIA}

\section{Aleson Pereira de Sousa}

Universidade Federal de Campina Grande (UFCG) aleson_155@hotmail.com

Submetido em 12/05/2020

Aceito em 28/07/2020 